\title{
APORTACIONES AL ESTUDIO DE LA SOCIABILIDAD CORAL EN LA ESPAÑA CONTEMPORÁNEA
}

por

\author{
JAUMe CARBonell I GUBERna \\ Universitat de Barcelona
}

RESUMEN: El canto coral ha sido un elemento de identificación colectiva para muchas comunidades europeas, que ba caracterizado su expresión cultural y ba contribuido en muchas ocasiones a tejer su destino bistórico. La relevancia de las asociaciones corales ha sido punto de interés e investigación desde diversos ángulos y realidades culturales. El presente trabajo no pretende ser una bistoria coral española, sino servir de reflexión sobre los recorridos realizados hasta abora en el estudio del fenómeno, para encauzar nuevas ideas y perspectivas en el estudio de la sociabilidad musical y coral. La España del siglo XIX era, como la actual, la suma de diferentes realidades nacionales con manifestaciones culturales distintas, y por tanto con maneras diferentes de ver y entender el canto coral que se manifestó y tomó cuerpo de manera muy distinta en las diferentes zonas donde nació; vivió desarrollos diferentes como diferentes fueron las historias, las formaciones sociales y las culturas de las que surgió.

Palabras Clave: Coralismo. España. Música. Orfeones. Siglos XIX y XX. Sociabilidad.

ABSTRACT: Choral song has been an element of collective identification for many European communities, characterizing their cultural expression and on many occasions contributing to the development of their historical destiny. The importance of choral associations bas been a point of interest and research from a number of different angles and cultural realities. This article does not aspire to be a bistory of choral song in Spain, but to serve as a reflection on the paths taken so far in the study of the phenomenon and to channel new ideas and perspectives in the study of musical and choral sociability. Nineteenth-century Spain was, like contemporary Spain., the sum of different national realities with distinct cultural forms of expression, and therefore with different ways of seeing and understanding choral song, which took on different shapes in the different zones where it evolved. It experienced as many different forms of development as there were different social formations and cultures.

KEY wORDS: Choral song. Spain. Music. Nineteenth century. Twentieth century. Sociability. 
En sí misma, la práctica de la música coral entraña un sentido de colectividad. Es un esfuerzo colectivo, cuyos logros e ilusiones se hacen extensivos a la comunidad de la que nace el coro y que se siente representada por sus cantos. La implicación del público sobrepasa su mero papel de espectador-receptor, e incorpora el coro, la sociedad coral, el orfeón, en su corpus simbólico, al igual que otros elementos de representación colectiva, como la bandera o el himno ${ }^{1}$. El canto coral ha sido pues un elemento de identificación colectiva para muchas comunidades europeas, que ha caracterizado su expresión cultural y ha contribuido en muchas ocasiones a tejer su destino histórico.

La relevancia de las asociaciones corales ha sido punto de interés e investigación desde diversos ángulos y realidades culturales, y ha sido objeto de estudio y materia de discusión en encuentros científicos que han servido para poner en común metodologías, líneas de investigación y resultados obtenidos ${ }^{2}$. El presente trabajo no pretende ser una historia coral española, sino servir de reflexión sobre los recorridos realizados hasta ahora en el estudio del fenómeno, para encauzar nuevas ideas y perspectivas en el estudio de la sociabilidad musical y coral.

Como es de suponer, al hablar de canto coral, manifestación coral o sociabilidad coral, nos referimos al movimiento de entidades corales surgidas de la sociedad civil. Las capillas religiosas y los coros profesionales o semiprofesionales de los teatros estables no pueden estar comprendidas bajo la misma denominación que las sociedades corales, orfeones o coros, y su estudio requeriría otros parámetros.

Privilegiaremos en este trabajo un esquema de tipo cronológico, desde las primeras manifestaciones corales protagonizadas por Clavé hasta 1936, fundándonos en nuestras propias investigaciones y en los trabajos que nos han sido asequibles.

\section{PRIMER PERÍODO: ENTRE 1850 Y 1874}

La primera manifestación coral aparecida en este sentido al sur de los Pirineos tuvo lugar en Cataluña de la mano de Josep Anselm Clavé [1824-1874], fundador y director de la Sociedad Coral La Fraternidad en Barcelona en 1850 (y que en 1857 pasó a llamarse Sociedad Coral Euterpe), a partir de la cual se desencadenó por toda la geografía catalana un movimiento musical popular. El

1 Ver Álvarez JUNCO, José: «La creación de los símbolos nacionalizadores en el siglo XIX español», en GUEREÑA, Jean-Louis (Ed.): Les nationalismes dans IEspagne contemporaine. Idéologies, mouvements, symboles, Paris, Éditions du Temps, 2001, pp. 63-68.

2 GuEREÑA, Jean-Louis (Ed.): Sociétés musicales et chantantes en Espagne (XIX ${ }^{e}-X X^{e}$ siècles), Número monográfico del Bulletin d Histoire Contemporaine de lEspagne, Bordeaux, $\mathrm{n}^{\circ} 20$, Diciembre de 1994, pp. 31-140; CARBONELl I GuBERNA, Jaume (Ed.): Els origens de les Associacions corals a Espanya (s. XIX-XX), Barcelona, Oikos-tau, 1998, 244 p. (ver GuEREÑA, Jean-Louis: «De París a Barcelona (1993-1996). El proyecto Sociedades musicales y cantantes», Ibid., pp. 9-14).

Hispania, LXIII/2, núm. 214 (2003).485-504 
estudio realizado sobre el nacimiento y el desarrollo del canto coral en Cataluña entre 1850 y 1874 aporta los datos necesarios para conocer las circunstancias de la fundación y el desarrollo que significó la primera fase del movimiento coral en Cataluña ${ }^{3}$.

Una base social obrera y popular deshumanizada en la sociedad industrial, necesitada de referentes culturales y de ocio, necesitada también de estructuras que encauzaran su toma de conciencia de clase en vistas a jugar su papel en el proceso de crecimiento y construcción nacional que vivía la Cataluña de mediados de siglo XIX, fue sin duda un condicionante propicio para la propagación del primer movimiento coral. Pero también lo fueron la creciente actividad asociativa burguesa de carácter musical, de la que la Sociedad Filarmónica de Barcelona sería el claro referente ${ }^{4}$, así como la proliferación de numerosas entidades o grupos más o menos estables de música popular urbana del tipo charanga o rondalla, que eran especialmente activas en Carnaval, Pascua, las verbenas veraniegas y el ciclo navideño.

El propio Clavé nos cuenta en sus escritos cómo una vez que obtuvo fama como guitarrista y cantante de café, fue reclamado en 1845 por unos jóvenes que formaban una de tales rondallas para que les dotara de repertorio y ejerciera de director ${ }^{5}$. Esta primera estudiantina fue La Aurora, que sería el precedente de la sociedad coral La Fraternidad, de 1850, lo que desmentiría la lectura romántica que se ha hecho repetidamente de la fundación del movimiento coral siguiendo una voluntad redentora preconcebida ${ }^{6}$.

Es conocida, igualmente, la rápida difusión del fenómeno en Cataluña, desde la misma ciudad de Barcelona, hasta las zonas más alejadas, de forma radial y siempre siguiendo las rutas de la presencia industrial, lo que nos evidencia uno de los caracteres esenciales del movimiento coral catalán de la primera generación: su base social eminentemente obrera. La aceptación e implantación del fenómeno se apoyaba en diversos factores a tener en cuenta: por un lado, la novedad del género, el espectáculo que podia ofrecer Clavé al frente de sus coros, era sorprendente, en cuanto a forma y repertorio, un género popular nuevo que entraba muy bien en el público, especialmente a partir de 1854 (a partir de La Font del Roure), año en el que Clavé empezó a escribir los

3 Carbonell i Guberna, Jaume: Josep Anselm Clavé i el naixement del cant coral a Catalunya (1850-1874), Cabrera de Mar, Galerada, 2000, 798 p. Es el resumen de una tesis doctoral presentada en la Universidad de Barcelona en 1996.

4 Hemos estudiado el papel de la entidad citada en la vida musical barcelonesa en CARBONELL, Jaume: «La societat Filharmònica de Barcelona, una entitat peonera i model de l'associacionisme musical a Catalunya, als 150 anys de la seva fundació", Revista de Catalunya, Barcelona, $\mathrm{n}^{\circ}$ 87, Julio-Agosto de 1994, pp. 108-118.

5 No entraremos en la biografía de Clavé, por otra parte conocida y publicada, peró sí recordaremos la publicación de sus escritos por entregas en la edición de 1863: Clavé, Josep Anselm: «Las sociedades Corales en España», El Metrónomo, Barcelona, n 3, 25-I-1863, p. 2.

6 Carbonell i Guberna, Jaume: Josep Anselm Clavé, op. cit., pp. 61-84. 
textos de sus composiciones y canciones en catalán, estrechando los lazos todavía más con el público; por otro lado, la función social que realizaron estos coros.

La rápida proyección del movimiento claveriano cristalizó en 1860 en la creación del primer órgano federativo, la Asociación Euterpense, que a su vez, fue un instrumento de proyección y de consolidación, como demuestra en sí mismo el propio periódico de la entidad, El Metrónomo, así como los festivales que Clavé organizó en Barcelona durante los años 1860 y $1864^{7}$. La vistosidad de los festivales como elemento de propaganda disparó el aumento de sociedades corales incluso fuera del Principado de Cataluña. A título orientativo, el censo de sociedades corales adscritas a la Asociación Euterpense que publica $E l$ Metrónomo con motivo del Festival de 1864 , ascendía a $85^{8}$, siendo entre las sociedades más importantes La Fraternidad (Gracia), El Porvenir (Sants, 1852), La Unión (Sabadell, 1855), y la del Centro de Lectura de Reus (1860)9, por citar sólo algunas.

La etapa final de la vida de Clavé, los diez últimos años de su vida, fueron marcados por la crisis. A la intensificación de la actividad política de Clavé se sumó la crisis económica desencadenada en 1865 , y la poca capacidad de renovación del canto coral en el panorama musical catalán. A partir de 1868, Clavé ejerció cargos en la vida política que le alejaron del centro de la actividad coral, lo que mermó la presencia ciudadana de la Sociedad Coral Euterpe, hecho que se repercutiria en las otras sociedades corales. El fin de la $I^{a}$ República supondría un agravamiento de la crisis, a la que se sumaría la muerte de Clavé pocas semanas después. El movimiento coral en Cataluña después de la muerte de Clavé es un capítulo todavía por investigar, y sin duda su estudio nos puede iluminar aspectos hoy todavía imprecisos del período 1874-1939.

La cronología de la primera vida coral catalana nos da pié a reflexionar sobre las características del movimiento a nivel social, organizativo y musical. Hemos apuntado anteriormente la condición eminentemente obrera de la base social de los coros de Clavé. Sobre el papel, no había una orientación ideológica concreta ni tampoco una adscripción política determinada; más bien al contrario, Clavé se esforzó repetidamente por negar la condición política de los coros que lideró. A pesar de ello, a nadie se le escapa el conocido republicanismo del fundador que le valió diversas estancias en presidio, y por el que ejerció cargos de responsabilidad entre 1868 y 1874.

No nos ha llegado ningun censo de miembros de ninguna sociedad coral de esta época que nos permita dilucidar la situación social o la ocupación de sus

\footnotetext{
7 El estudio de los festivales así como del papel que supuso la Asociación Euterpense está estudiado en Carbonell i Guberna, Josep Anselm Clavé, op. cit., pp. 233-330 («El desenvolupament córal durant el període 1860-1864»).

8 El Metrónomo, Barcelona, $\mathrm{n}^{\circ}$ 64, 5-VI-1864, pp. 5-6.

9 Ver DuARDE, Ángel: «Republicanismo y canto coral en el Reus de finales del siglo XIX», Bulletin d'Histoire Contemporaine de l'Espagne, Bordeaux, $\mathrm{n}^{\circ} 20$ [Sociétés musicales et chantantes en Espagne (XIX'-XX' siècles)], Diciembre de 1994, pp. 94-109.
} 
componentes, pero por los títulos de alguna sociedades con claras referencias a ocupaciones artesanas o industriales (blanqueros, veleros, tejedores de velos, taponeros -industria del corcho- etc.) y por las descripciones de algunas fuentes (la misma revista El Metrónomo en la mayoría de los casos), llegamos a pensar que la composición social de los coros claverianos del período al cual nos referimos abarcaría una amplia franja entre la menestralía y el proletariado industrial. La misma ambigüedad la encontramos en las "posiciones políticas» (nunca manifestadas abiertamente, pero a pesar de ello se pueden entrever ciertas actitudes) que irían desde la sumisión demostrada en forma de serenatas dedicadas a personas destacadas del poder militar, económico o político, hasta la participación en huelgas y la postura solidaria del coro, o los enfrentamientos con la Iglesia en Montblanc o el obispado de. Vic por ejemplo.

La idea de la redención del obrero a través de la cultura y el arte, propia del universo coral europeo y de otras iniciativas populares, fue un elemento subyacente en el movimento coral catalán de la primera época, aunque éste no hubiera nacido necesariamente con tal propósito. La masa social en su inmensa mayoría era analfabeta, cumplía horarios laborales abusivos y no disponía de medios para el ocio y la cultura. Una de las funciones sociales que llenó la sociedad coral fue precisamente cubrir estas deficiencias del sistema. Numerosas sociedades corales destinaban, además de laś horas de ensayo propiamente, una atención especial a la instrucción popular (el caso que podemos conocer más por la importancia de la entidad es el de la Sociedad Coral del Ateneo Catalán de la Clase Obrera, con un completo programa de enseñanzas), y evidentemente a los conocimientos musicales. Prácticamente, todos los coros llegaron a disponer de un local social para reunirse, ensayar o estudiar, y algunos contaron con biblioteca, teatro, etc.

Por lo que se refiere a las características musicales, los coros de Clavé fueron integrados por voces masculinas y con un repertorio formado casi exclusivamente por obras de Clavé, excepto en algunos casos en que la Sociedad Coral Euterpe requería la colaboración de la sección de mujeres del coro del Liceo, hecho que no se puede hacer extensivo al resto de entidades corales. Podían interpretar también coros de ópera - se reconoce a Calvé el hecho de haber sido el primero en dar a conocer la música de Wagner en Cataluña, con el estreno de fragmentos corales del Tannbäuser en 1862 - o alguna composición del director o músico local (hecho que se acentuó notablemente con motivo de los concursos corales del 1862 y 1864), pero la característica propia era la exclusividad del repertorio claveriano, al que sólo podían acceder las entidades integradas en la Asociación Euterpense.

La aportación de Clavé, como lo es su figura, tiene diferentes puntos de interés. Por un lado, el más visible, como compositor. Sus composiciones conocidas (alrededor de unas ochenta) crearon un género que ha tenido numerosos seguidores y que ha constituido uno de los referentes musicales en la música catalana hasta hoy. Por otro lado, el femómeno de las sociedades corales desde el punto de vista social, ha tenido una vida que llega hasta la actualidad y que 
ha vivido su propia historia, sus ramificaciones y diversificación en función de los cambios sociales y musicales.

Evidentemente, antes de 1850 ya había asociaciones populares, pero la irrupción de las sociedades corales en el panorama asociativo capitalizó e incrementó la sociabilidad popular de tipo asociativo en Cataluña. Las sociedades corales como hemos visto asumieron flaquezas del sistema, como la enseñanza, pero también la cobertura sanitaria o asistencial, así como también actuaron en muchos casos de fuerza sindical solapada, recaudadora de fondos en épocas de conflictividad, etc.

Algunos trabajos sobre música coral catalana; especialmente los realizados desde fuera de Cataluña, han tendido a sobredimensionar la figura y la aportación de los hermanos Pedro y Juan Tolosa, fundadores e impulsores del Orfeón Barcelonés en 1853. En 1863, los hermanos Tolosa y Clavé protagonizaron una dura polémica sobre la paternidad de la práctica coral en España, así como la conveniencia e idoneidad de los respectivos métodos utilizados. Clavé esgrimía la fecha de 1850 como fundación de la primera sociedad coral, por delante de la fundación del citado Orfeón tres años después. Por su parte, los hermanos Tolosa apuntaron la fundación de dos entidades antecedentes del Orfeón Barcelonés (Euterpe y Talía) y el Concierto Barcelonés fundadas en 1848, y las reivindicaban como iniciadoras de la práctica coral. En nuestro trabajo ya citado $^{10}$, demostramos que las actividades de las entidades mencionadas no pueden considerarse asociaciones de canto coral y más bien sus actividades se situan como seguidoras de la línea estética y sociomusical de la Sociedad Filarmónica de Barcelona, es decir academias musicales de carácter burgués con alguna intervencion coral operística o religiosa.

La disputa por la fecha inicial del canto coral está clara, a favor de Clavé pues, y hasta aquí la discusión está cerrada. Ahora bien, lo que nos es más interesante para nosotros es la cuestión del modelo de enseñanza y de práctica coral que tenían ambos. Muy acorde con las formaciones personales da cada uno. Clavé fue autodidacta, mientras que los hermanos Tolosa tuvieron una formación musical tradicional o clásica. Para Clavé, la enseñanza musical tradicional era secundaria. Algunas sociedades corales enseñaban solfeo a sus coristas pero no era una prioridad. La piezas se enseñaban de oído y se memorizaban, puliendo en la medida de lo posible la interpretación. Para los hermanos Tolosa, en cambio, la razón de ser del Orfeón Barcelonés era precisamente la enseñanza musical. El Orfeón Barcelonés se basaba en el método de enseñanza elaborado en 1829 por Guillaume Louis Bocquillon-Wilhem [1771-1842] y que Juan Tolosa había conocido durante sus estudios en Marsella y París. Mientras que la voluntad de Clavé era que sus coristas cantaran y valoraran la inmediatez del resultado, para los Tolosa la prioridad era formar buenos solfistas.

10 Carbonell i Guberna, Jaume: Josep Anselm Clavé, op. cit., pp. 651-680 («La polèmica amb l'Orfeón Barcelonés dels germans Pere i Joan Tolosa»).

Hispania, LXIII/2, núm. 214 (2003) 485-504 
Más allá de las diferencias en el modelo de enseñanza, también hubo diferencias a nivel organizativo. El Orfeón Barcelonés gozó de la protección del Ayuntamiento de Barcelona que vio en él una manera de contrarrestar, sin éxito desde luego, la creciente incidencia de las sociedades corales del republicano Clavé en la sociedad catalana. Según sus propias fuentes, estaba también formado por gentes trabajadoras, y el repertorio no difería demasiado de las sociedades corales claverianas. El Orfeón Barcelonés y los pocos que le siguieron cantaban básicamente obras de Tolosa, algun coro de ópera y música religiosa, eso sí, cosa que en los claverianos era mucho frecuente. Los espectáculos del Orfeón Barcelonés se revestían de una aureola más «culta» que los de Clavé, aunque con el curso de los años y a tenor del éxito de Clavé, los Tolosa acabaron imitando el estilo de Clavé en sus actuaciones en los jardines del Paseo de Gracia.

Insistimos en lo que decíamos al iniciar este apartado: a pesar de que algunos estudiosos han sobrevalorado el fenómeno Tolosa, la incidencia que tuvo en la vida musical catalana fue mínima. Contó con seguidores, eso sí, pero solamente podemos decir que fueran de relevancia en Lleida, donde el impacto claveriano fue menor ${ }^{11}$. El Orfeón Barcelonés dejó de existir durante el verano de 1867 y los hermanos Tolosa siguieron sus actividades musicales tal como habían comenzado, en el mundo de la academia musical, y ya sin ninguna vinculación con el mundo coral.

Como se desprende del trabajo publicado por María Nagore en $1995^{12}$, a excepción de algunos casos puntuales, especialmente de influencia catalana inmediata como en Castellón o Zaragoza, en el resto peninsular la expansión del coralismo siguió más el modelo de Tolosa que el de Clavé. Y pensamos que más por causa de la influencia francesa del Orphéon parisino y el método Wilhem que por mérito de sus valedores barceloneses. Como en el caso catalán, en el estudio del canto coral vasco observamos una época inicial de formación situable en los años centrales del siglo XIX, y una etapa de crecimiento durante los años sesenta ${ }^{13}$. Como apunta también María Nagore, el surgimiento del orfeonismo vasco se daría con independencia del catalán ${ }^{14}$, y compartiría unos antecedentes que abarcaría desde un asociacionismo musical hasta las charangas, comparsas y rondallas músico-festivas.

.11 TRENC BALlester, Élisée: «La Renaixença et l'implantation du chant choral à Lérida», Bulletin d'Histoire Contemporaine de IEspagne, Bordeaux, $\mathrm{n}^{\circ} 20$ [Sociétés musicales et chantantes en Espagne (XIX'-XX $X^{e}$ siècles)], Diciembre de 1994, pp. 79-93.

12 NAGORE, María: «Historia de la música coral en España en el siglo XIX», en La música española en el siglo XIX, Oviedo, Servicio de publicaciones de la Universidad de Oviedo, 1995, pp. 325-462.

13 BAGÜES, Jon: «El coralismo en España en el siglo XIX», en CASARES RODICIO, Emilio, FERNÁNDEZ De LA CUESTA, Ismael, y LóPEZ-CALO, José (Eds.): Actas del congreso internacional «España en la música de Occidente», Madrid, Instituto Nacional de las Artes Escénicas y de la Música, 1987, vol. 2, p. 186.

14 NAGORE, María: «El origen de las sociedades corales en el País Vasco», en CARBONELL I GuBERNA, Jaume (Ed.): Els origens de les associacions corals a Espanya, op. cit., p. 149. 
De manera aislada, en 1855 se fundaría el primer coro bilbaíno, con el precedente directo de una sociedad filarmónica. Se trataría pues de un caso atípico y aislado, en relación con la actividad musical y la sociabilidad burguesa que buscaba posiblemente ampliar horizontes musicales, si bien el hecho de organizar un coro, con composiciones propias incluso, le daba algo más de relieve que lo que podía ser una simple sección de la sociedad filarmónica.

Apoyaría el carácter de excepcionalidad de este primer orfeón, el largo período de tiempo que pasaría hasta 1862, en que se fundaría un Orfeón en Bilbao y también la Sociedad Coral La Armonía, ya esta última con unos objetivos relacionables con el movimiento catalán y el orfeonismo francés, las ideas de los cuales ya habían llegado al País Vasco, aunque de manera imprecisa según cita María Nagore, entre los que se. encontraba el de abrir una escuela de música gratuita $^{15}$. Este hecho, y el de dirigirse no solamente a las clases populares sino a un amplio sector de la población, dando cabida también a los músicos profesionales, hace pensar a la autora en la mayor proximidad con el proyecto de los hermanos Tolosa en Barcelona.

La década de los sesenta sería pues la etapa de crecimiento en la actividad coral, tal como podemos ver en otras zonas, pero siempre capitalizando la actividad las ciudades importantes - Bilbao, San Sebastián, Pamplona (Orfeón de Obreros, de Santa Cecilia; o el Orfeón Easonense fundado en 1865 y a través del cual observamos el inicio del interés por la música popular; Orfeón Pamplonés, también fundado en 1865). Constatamos así el carácter independiente, en relación con el catalán, del canto coral vasco de esta primera época, tanto en la forma en que apareció como en sus objetivos.

Siempre según el estudio de María Nagore, el movimiento coral vasco vivirá una época de recesión a partir de los años setenta, para resurgir con fuerza renovada y nuevos planteamientos a partir de los años 1880 hasta el final del siglo XIX, la segunda etapa de la que nos habla Bagües.

Hemos visto cómo las primeras manifestaciones corales que se dan en la Península se enmarcan en la línea europea, si bien con lecturas independientes. Clavé, Tolosa y las manifestaciones aisladas del País Vasco eran diferentes lecturas del femomeno coral europeo que tuvieron lugar de manera independiente una de la otra, y en algún caso en claro antagonismo. Las dos únicas manifestaciones que apuntaron hacia un desarrollo coral más generalizado a nivel territorial fueron las dos opciones catalanas, muy posiblemente animadas por la competencia que se profesaban mútuamente. Tanto los hermanos Tolosa como Clavé presumieron de contar con formaciones corales en el País Valenciano, en Zaragoza, en Madrid e incluso en Cuba. Aun así, el reconocimiento de dicha expansión ha recaído en Clavé nuevamente, posiblemente por la rápida extinción del Orfeón Barcelonés en 1867 y la permanencia de los valores claverianos después de su muerte. Incluso hoy en día, los llamados Coros Clave [sic, sin

15 Ibid., pp. 149-150.

Hispania, LXIII/2, núm. 214 (2003) 485-504 
acento] dedicados a la música popula cubana, son una reminiscencia de los primeros coros fundados por catalanes en Cuba.

En Valencia, se fundaría el Orfeón Valenciano siguiendo el modelo del Barcelonés en 1862, y el mismo año en Vinaròs, la Sociedad Coral El Maestrazgo. Un año después, se fundaría en Zaragoza la Sociedad Coral La Coronilla, seguidora de Clavé ${ }^{16}$. El pulso entre Tolosa y Clavé se desplazó también a tierras valencianas, pero sólo hasta la segunda mitad de los años 1860 en que desaparecieron ${ }^{17}$. No conocemos, por el momento, un estudio sistemático y actualizado del canto coral en Valencia, a excepción de algunas aportaciones puntuales y de puesta al día de la información como los trabajos en esta dirección de Vicent Galbis ${ }^{18}$.

Otro tanto cabría decir de la situacion en las Islas Baleares. En 1866, la Sociedad Coral Palmesana y el Orfeón Republicano Balear iniciaron un recorrido coral que conservaría lazos con el movimiento claveriano ${ }^{19}$. En este sentido, tenemos que hacer referencia también a los trabajos de Joan Company sobre la música en las Islas Baleares y el canto coral en particular ${ }^{20}$.

Generalmente, los trabajos que se han realizado con la voluntad de abarcar la historia coral de todo el territorio español han puesto en evidencia la inviabilidad del propósito, por el desajuste cronológico y la dificultad a la hora de aventurar una periodización viable. Mientras en Cataluña, durante los años 1850-1874, se vive la etapa de crecimiento y desarrollo con la posibilidad de convivir diversas opciones de entender el canto coral e incluso está en condiciones de exportar el proyecto a su área de influencia inmediata, en Castilla (nos referimos a Castilla en el sentido cultural o «nacional» del término, no en el artificioso y falso compartimiento autonómico actual, es decir siguiendo lo que el conocido mapa de España de 1854 conservado en la Biblioteca Nacional de Madrid llama La España Uniforme o Puramente Constitucional que comprende estas treinta y cuatro Provincias de las coronas de Castilla y León, iguales en todos los ramos económicos, judiciales, militares y civiles), durante el período que María Nagore

16 Ver López GonZÁlez, Juan-Jaime y García LASAOSA, José, Orígenes del movimiento obrero en Aragón (1854-1890), Zaragoza, Institución «Fernando el Católico», 1982, pp. 115-125 («La sociedad coral obrera "La Coronilla»), y EGIDo LANGarita, María José: «Aportaciones al origen del feómeno coral en Aragón: Sociedad Coral La Coronilla», en La Investigación musical en España: Estado de la cuestión y aportaciones. Actas del IV ${ }^{\circ}$ Congreso de la Sociedad Española de Musicología, Revista de Musicología, Madrid, Vol XX, $\mathrm{n}^{\circ} 1,1997$, pp. 571-578.

17 CARbOnell, Jaume: «El cant coral», en AviÑOA, Xosé: Història de la Música Catalana, Valenciana i Balear, vol. III. Del Romanticisme al Nacionalisme, Barcelona, Ed. 62, 2000, pp. 147-186.

18 GaLBIS, Vicent: «Un referent per als orfeons valencians», El Temps, n 787, 13 al 19 de Julio de 1999, pp. 48-49, y "El movimiento coral valenciano en el siglo XIX: orígenes y consolidación», en Carbonel., Jaume (Ed.): Actes del $1^{\text {er }}$ Congrés Català de Cant Coral, Barcelona, 1999 (en prensa).

19 CARBONELl, Jaume: «El cant coral», op. cit.

20 COMPANY, Joan: "El cant coral a Mallorca: personatges i institucions», en Historia del cant coral a Mallorca, Madrigal, Palma de Mallorca, $\mathrm{n}^{\circ}$ 1, 1993, y «El cant coral a les Illes Balears», en Carbonell, Jaume (Ed.): Actes del $1^{\text {er }}$ Congrés Català de Cant Coral, op. cit. 
llama de formación («Los primeros orfeones (1850-1868»)21, sólo se fundan un par de orfeones según Joaquina Labajo; en Andalucía, se crea uno en Málaga..., y Asturias está todavía por despertar.

El trabajo de Joaquina Labajo Valdés sobre el movimiento coral en Valladolid (con una introducción sobre el orfeonismo en toda España) no nos ilustra en realidad sobre la situación coral en Castilla ${ }^{22}$. Y, a pesar del título, tras una introducción general, el libro se ciñe concretamente al estudio de la actividad coral en Valladolid, tal como reza el subtítulo del trabajo. La información de la que disponemos hoy por hoy sobre la actividad coral en Castilla es pues muy pobre, tanto en estos años como en el primer tercio del siglo $\mathrm{XX}$, a tenor sin duda del poco desarrollo que hubo.

Según María Nagore, los principales focos de crecimiento coral fueron la zona mediterránea y la cantábrica, y la explicación es obvia y estamos plenamente de acuerdo con Joaquina Labajo cuando relaciona el movimiento coral con el desarrollo industrial, la presencia obrera y, posteriormente lo veremos, el nacionalismo. Es decir, como señalábamos al principio, que el canto coral se vincula claramente con la voluntad de afirmación colectiva, social o nacional.

\section{SEGUNDO PERÍOdo: la ReSTAuración, el MODERnismo, hasta la GuE- RRA CIVIL}

Al enfrentarnos al estudio del período que María Nagore califica de «crecimiento" (los años 1870-1900), observamos igualmente la imposibilidad de generalizar la cronología. Orientativamente, hemos citado la periodización utilizada por María Nagore aunque preferimos matizar los límites cronológicos. Nos parece en efecto más acertado iniciar el período en 1874 que en 1870 . El final de la I ${ }^{a}$ República constituye un cambio en la vida política y social importante, que se reflejará también en la vida asociativa. Por otro lado, 1900 tampoco nos parece una fecha muy significativa ${ }^{23}$. Si bien puede considerarse una de las fechas de referencia del Modernismo, cabría tomar este concepto de manera amplia, salvando todos los matices, y no encontraríamos otro corte histórico que pudiera ser considerado común hasta 1923, y más claramente hasta 1936-1939.

21 NAGORE, María: «Historia de la música coral en el siglo XIX», op. cit., p. 436.

22 LABAJO VALDÉs, Joaquina: Aproximación al fenómeno orfeonístico en España (Valladolid 18901923), Valladolid, Diputación Provincial de Valladolid, 1987, 373 p. Ver una presentación del libro por BREY, Gérard: «Sur les orphéons en Espagne en général et à Valladolid en particulier. Commentaires à propos du libre de Joaquina Labajo Valdés", Bulletin d'Histoire Contemporaine de lEspagne, Bordeaux, $\mathrm{n}^{\circ} 20$ [Sociétés musicales et chantantes en Espagne (XIX'-XX' siècles)], Diciembre de 1994, pp. 38-46.

${ }_{23}$ Ver no obstante Salaún, Serge y Serrano, Carlos (Eds.): 1900 en España, Madrid, EspasaCalpe (Espasa Universidad 23), 1991, 233 p.

Hispania, LXIII/2, núm. 214 (2003) 485-504 
En Cataluña, 1874 fue un año especialmente negativo para el mundo coral. No solamente representó el fin de la $I^{\mathrm{a}}$ República sino que pocas semanas después moriría Clavé, dejando la institución coral en una situación de crisis que se arrastraba desde hacía unos años, agravada ahora con la nueva situación política, lo que hacía temer por su continuidad. Podemos advertir la situación de crisis si observamos el poco número de coros que asistieron al entierro de Clavé, realizado con discreción pero con solemnidad ${ }^{24}$.

Sin embargo, poco a poco la actividad coral se fue retomando, y aunque no se llegara a la euforia de los años 1860 , se recuperó una cierta estabilización de la actividad, eso sí, agravada por las luchas internas en el seno de la Asociación Euterpense, el organismo federativo que agrupaba los coros claverianos fundado por Clavé en 1860, con las consecuentes escisiones y reagrupaciones diversas que marcaron la vida coral claveriana hasta 1936.

La crisis también se dejó ver en el terreno musical. Los Coros de Clavé se cerraron en una endogamia, un culto a la personalidad, venerando y mitificando al fundador, a la tradición heredada, y negando toda posibilidad de renovación, tanto de repertorios como de planteamientos musicales. El resultado es conocido. Las inquietudes de los músicos jóvenes en el terreno coral no tenían cabida en los coros de Clavé, hecho que cristalizó en el conocido concurso coral celebrado en 1888, en el que Lluís Millet y Amadeu Vives descubrieron nuevos horizontes en la interpretación coral, que les llevó a la fundación del Orfeó Català en $1891^{25}$, una entidad que reconocía la herencia claveriana (en ningún momento renegaron ni de Clavé ni de su obra) pero que aspiraba a llegar más lejos.

El Orfeó Català nacía en una Barcelona que ya no era la que acuñó las sociedades corales claverianas. La burguesía que había crecido con la industrialización necesitaba una expansión política que no cabía en la España de la Restauración, y las ideas de la Renaixença habían sido asumidas por un amplio sector de la sociedad catalana. Es en este auge del nacionalismo de finales del siglo XIX cuando hay que situar el nacimiento del Orfeó Català, que, de por sí, tiene sustanciales diferencias con los coros claverianos. Por un lado, la composición social, más acomodada, y con una formación cultural y musical de sus miembros más competente, lo cual se traduce directamente en el repertorio. Y por otro, el componente ideológico, nacionalista conservador, a diferencia de los coros de Clavé de adscripción más republicana.

El repertorio del Orfeó Catalá es un reflejo de estas premisas esenciales: canciones patrióticas ${ }^{26}$, recuperación del legado tradicional, y la música sinfóni-

24 Carbonell i Guberna, Jaume: Josep Anselm Clavé, op. cit., pp. 556-562.

25 La formación y el desarrollo del Orfeó Català, así como de los numerosos orfeones que siguieron sus pasos en Cataluña, ha sido estudiado por Pere Artís en numerosos trabajos, siendo el más completo: ARTís, Pere: El cant coral a Catalunya (1891-1979), Barcelona, Ed. Barcino, 1980.

26 MARTORELL, Oriol: «La consciència d'Himne Nacional», en Els Segadors, himne nacional de Catalunya, Barcelona, Publicacions de l'Abadia de Montserrat - Generalitat de Catalunya, 1993, pp. 49-76; CARbonell, Jaume: «Els Cors de Clavé i Els Segadors entre 1892-1936. Contribució a 
co-coral europea, con un especial interés por la música religiosa, con la consiguiente ampliación del espectro vocal a voces mixtas, necesaria para afrontar este amplio y ambicioso repertorio, que convirtió al Orfeó Catalá en una pieza clave en el desarrollo musical catalán de finales del siglo XIX y hasta la actualidad. Cabe decir que la expansión del modelo ideado por Millet y Vives también disfrutó de una importante implantación en Cataluña que llevó a la creación de la Germanor dels Orfeons de Catalunya en $1918^{27}$. Entre los orfeones más significativos, cabe destacar el Orfeó de Sants (1899), el Orfeó Gracienc (1903), el Orfeó Manresà (1901), el Orfeó Vigatà (1902), entre muchos otros.

La convivencia en Cataluña de los dos modelos corales cubría las aspiraciones vitales y estéticas colectivas de diferentes grupos sociales. Los Coros de Clavé respondían a un carácter más social, obrero, republicano y más bien «españolista», mientras que los orfeones liderados por el Orfeó Català representaban un sector social más acomodado, más culto, catalanista y conservador. La presencia o implantación social de ambas opciones fluctuó en función de la situación social y política del país, y, también hay que deirlo, con algunos episodios de amistoso enfentamiento ${ }^{28}$. La posición de superioridad del Orfeó Català en la implantación social en Barcelona con respecto a los coros de Clavé se invirtió de manera muy clara en los años de la II ${ }^{a}$ República.

A pesar del momento propicio que se vivió en Cataluña de difusión y espansión de los orfeones, en Valencia, durante los últimos años del siglo XIX, vemos una clara penetración del canto coral pero de signo claveriano, gracias a la presencia en Valencia del director catalán Joan Goula. La visita de los Coros de Clavé en Valencia en 1893 propició la fundación del Orfeón Valenciano de la Vega y del Orfeó El «Micalet», con la dirección artística y la presidencia honoraria de Salvador Giner. La presencia del calverianismo en Valencia fue una realidad hasta la creación de la Asociación Coral de la Región Valenciana en 1896, que funcionó durante dos escasos años. Y en 1920, coros valencianos volvieron a vincularse federativamente con los catalanes ${ }^{29}$.

El reflejo del Orfeó Català se vio mucho más claro en las Islas Baleares de la mano de Antoni Noguera, fundador de la Capella de Manacor en 1897, con un notable movimiento orfeonístico inspirado en el catalán que dio lugar a finales del siglo XIX a numerosas entidades (como el Orfeó de Porreres, el Orfeó Llucmajorer, el Orfeó Mallorquí, el Orfeó Pollencí, etc.), seguidoras del Orfeó

\footnotetext{
l'estudi de la conciència d'himne nacional de Catalunya», en AviÑOA, Xosé (Ed.): Miscel.lània Oriol Martorell, Barcelona, Universitat de Barcelona, 1998, pp. 171-188.

27 Pere Artís ha estudiado el fenómeno de los orfeones en la obra ya citada así como la figura y personalidad de Lluís Millet. Ver ARTís, Pere: El cant coral a Catalunya, op. cit., y Lluís Millet vist per Lluís Millet, Barcelona, Ed. Pòrtic, 1983.

28 Hemos trabajado este aspecto que afecta a la adscripción política y al repertorio en CARBONELL, Jaume: «Els Cors de Clavé i Els Segadors entre 1892-1936», op. cit.

29 CARBONELL, Jaume: «El cant coral», op. cit., pp. 183-184, y GaLBIS, Vicente: «Un referent per als orfeons valenciasns», op. cit.
}

Hispania, LXIII/2, núm. 214 (2003) 485-504 
Català y con un espíritu y unos objetivos sociales y musicales paralelos. En cambio, la presencia claveriana se vería apoyada por la fundación del Orfeó Maonès en 1890, adherida a los Coros de Clavé30.

Al estudiar el caso del orfeonismo vasco, nuevamente nos encontramos con problemas de encuadramiento cronológico si queremos generalizar. Gotzon Ibarretxe nos habla de un primer período en la historia del coralismo vasco que comprendería desde los inicios de mediados del siglo.XIX, a los que ya nos hemos referido, hasta las primeras décadas del siglo $\mathrm{XX}^{31}$. Durante el último tercio del siglo XIX, y después de la segunda guerra carlista, según cita María Nagore $^{32}$, el renacimiento cultural vasco coincidiría con la Renaixença en Cataluña y estaría acorde con los movimientos nacionalistas europeos que afloran durante el siglo XIX.

Es durante este período cuando, según Nagore e Ibarretxe, se situa el auge del movimiento coral vasco de mayor importancia con un contenido eminentemente vasquista, con las fundaciones de los principales orfeones vascos como el Orfeón Bilbaíno en 1886, el Orfeón Pamplonés en 1892, el Orfeón Donostiarra en 1897, el Orfeón Vitoriano, el Orfeón Durangués en 1882, el Orfeón Eibarrés en 1883, el Orfeón de Munguía en 1896, el Orfeón Renteriano en 1898, el Centro Musical Tolosano en 1901, y el Orfeón de Gernika en 1903, entre muchos otros. En este sentido y sin que tenga una relación directa, podemos establecer coincidencias ideológicas con los orfeones catalanes, a partir de 1891 con el caso del Orfeó Català y sus seguidores.

La estructura social y económica del País Vasco en este momento, junto con el hecho de que no hubiera una entidad líder ni tampoco un organismo federativo que aglutinara el movimiento, explicaría la diversidad de entidades de distinto carácter. La actividad política favoreció la multiplicación de orfeones ya que organizaciones políticas formaron sus coros, apareciendo así los orfeones socialistas ${ }^{33}$, los carlistas o los católicos, con un repertorio y una función social determinados por sus respetivas organizaciones.

La cuestión del repertorio de los orfeones vascos durante este período estaría determinada también en función del orígen o de la adscripción de la entidad. En líneas generales, la canción popular vasca y el teatro lírico serían los

30 CARbonell, Jaume: «El cant coral», op. cit., pp. 183-184. Joan Company ha trabajado notablemente sobre el canto coral en Mallorca, y en especial acerca de la Capella de Manacor y sù director Antoni Noguera. Ver COMPANY, Joan: «El cant coral a Mallorca», op. cit., y «El cant coral a les Illes Balears", op. cit.

31 IBARRETXE, Gotzon: El canto coral como entramado del nacionalismo musical vasco, Tesis doctoral, UPV/EHU, 1996, y «Orfeones, regionalismo, foralismo y nacionalismo», en CARBONELL, Jaume (Ed.): Actes del $1^{\text {er }}$ Congrés Català de Cant Coral (en prensa).

32 NAGORE, María: «El origen de las sociedades corales en el País Vasco», op. cit., pp. 143-155.

33 RALLE, Michel: «L'orphéonisme socialiste dans la zone de Bilbao (1890-1910)», Bulletin d'Histoire Contemporaine de lEspagne, Bordeaux, $\mathrm{n}^{\circ} 20$ [Sociétés musicales et chantantes en Espagne (XIX'$X X^{e}$ siècles)], Diciembre de 1994, pp. 128-140. 
pilares básicos que formarían el repertorio, contribuyendo al nacionalismo musical vasco (un hecho común en toda la Europa coral por otro lado), a la vez que a un creciente interés por el repertorio sinfónico-coral.

$\mathrm{La}$ incidencia de las entidades corales vascas se estabilizaría a partir de los primeros decenios del siglo XX, como señala María Nagore, por la aparición de nueva oferta lúdica y cultural popular como el cine o los deportes ${ }^{34}$; y los acontecimientos.políticos acaecidos entre 1923 y 1939 mermarían considerablemente su actividad. Cabe destacar, en este período, el papel que hicieron entidades como el Orfeón de la Juventud Vasca, o el Coro Nacional Vasco creado en 1937.

$\mathrm{El}$ orfeonismo asturiano se desarrollaría desde $1875^{35}$, tomaría fuerza durante los últimos veinte años del siglo XIX y muy especialmente con la entrada del siglo XX con las Asociaciones Musicales Obreras, vigentes desde 1901 en las principales ciudades asturianas. El orfeonismo asturiano es eminentemente obrero y las entidades pueden distinguirse según el fondo ideológico y su adscripción política. Jorge Uría, al estudiar los orfeones asturianos, se refiere sin embargo a la presencia de las asociaciones musicales obreras patrocinadas por la burguesía y con un claro contenido paternalista y de control ${ }^{36}$. Estudiando el carácter de los primeros coros asturianos, relaciona en efecto miembros de la nobleza española y familias importantes de la vida económica asturiana como protectores o patrocinadores de entidades corales determinadas ${ }^{37}$.

A principios del siglo XXX, también empiezan a proliferar en Asturias entidades corales en el seno de las Casas del Pueblo de las principales ciudades y poblaciones con base social obrera, con unos objetivos opuestos a los anteriores ${ }^{38}$. Y, del estudio de Jorge Uría, se desprende que el momento de mayor número de fundaciones de entidades corales en Asturias sería a partir de 1904, y que cristalizaría en la creación, al año siguiente, de la Federación Musical Asturiana, que intentaría agrupar y coordinar la actividad coral asturiana ${ }^{39}$, Aunque de hecho la entidad federativa no llegaría a tener un funcionamiento efectivo, posiblemente

34 NAGORE, María: «El origen de las sociedades corales en el País Vasco», op. cit., p. 153.

35 Un trabajo que ocupa un lugar destacado en la historiografia coral asturiana, es el de ARRONEs Pé́n, Luis: Historia coral de Asturias, Oviedo, Biblioteca popular asturiana, 1978.

36 URÍA, Jorge: «El proceso de formación de las sociedades corales en Asturias. De los inicios a los años treinta», en CARBONELL I GUBERNA, Jaume (Ed.): Els orígens de les associacions corals a Espanya, op. cit., pp. 179-225, y «La formación de coros en Asturias. Del siglo XIX a la Guerra Civil», en URíA, Jorge (Ed.), Asturias. Historia y Memoria Coral (1840-1936), Oviedo, Federación Coral Asturiana, 2001, pp. 33-104.

37 URÍA, Jorge: «El proceso de formación de las sociedades corales en Asturias», op. cit., pp. 195-196.

38 Para mayor información acerca de los orfeones socialistas, ver GUEREÑA, Jean-Louis: «Les orphéons socialistes et leur répertoire au début du $\mathrm{XX}^{\mathrm{e}}$ siècle», Bulletin d'Histoire Contemporaine de IEspagne, Bordeaux, $\mathrm{n}^{\circ}$ 20, 1994, pp: 112-127, y sobre todo «Música y socialismo. Los orfeones socialistas en Asturias a principios del siglo XX», en URÍA, Jorge: Asturias. Historia y Memoria Coral (1840-1936), op. cit., pp. 158-192.

39 URÍA, Jorge: «El proceso de formación de las sociedades corales en Asturias», op. cit., p. 201.

Hispania, LXIII/2, núm. 214 (2003) 485-504 
a causa de la diversidad de ideas y objetivos en el denso entramado coral asturiano, y la autonomía de cada una de las entidades, muchas de ellas albergadas en otras asociaciones de carácter político, cuya prioridad no era la música sino el destino social y político.

Después de la crisis en el seno de las asociaciones populares durante los años de la Primera Guerra Mundial, al final de los años veinte la frecuencia de fundaciones corales puede ser comparable a la de los primeros años de siglo. El resultado del incremento de actividad y de nuevas creaciones de asociaciones sería la reactivación de un órgano federativo, la Federación Provincial de Masas Corales ${ }^{40}$. Durante este período, las entidades corales que habrían superado la crisis pasarían a una mayor estabilidad y estructura, a diferencia de los muchos coros de la primera época, con un grado de efimeridad más acentuado. Los coros como el Orfeón Ovetense, bajo la dirección de Luis Ruiz de la Peña, el Coro Asturiano o el Afición, de Gijón, llegaron a un nivel destacable como se plasmó en concursos de nivel internacional ${ }^{41}$. La formación musical de entidades como el Orfeón de Mieres era bien curada. Los repertorios tendían a dar preferencia a los temas populares o de signo folklórico junto con obras de compositores europeos, desde la polifonía del siglo XVI hasta fragmentos operísticos.

La eclosión coral de la costa cantábrica llega también a Galicia en la época de la Restauración ${ }^{42}$. Si bien en fechas anteriores hay referencias a entidades corales de vida limitada (en 1863 se fundó así la Sociedad Coral Euterpe de Lugo, a inspiración de la idea claveriana ${ }^{43}$ ), es desde 1875 cuando empezamos a ver fundaciones de orfeones en las principales poblaciones como el Orfeón Coruñés (1875), el Orfeón Birgantino (1877), el Eco (1882), el Eslava (1882), el Orfeón Pontevedrés (1883), entre otros. En consonancia con el caso asturiano, el período de auge del orfeonismo gallego comenzaría en 1880, plasmado en el resultado de los principales orfeones gallegos en los certámenes celebrados durante este período, hasta los años veinte del siglo XX en que daría muestras de debilidad.

El caso coral gallego tiene pues su propia especificidad que lo singulariza. Cuenta con un entramado social difereñte al que podríamos encontrar en el caso catalán o asturiano, ya que la escasa presencia industrial en Galicia limitaba la proliferación de coros obreros, reducidos a centros de cierta concentración proletaria como A Coruña o Vigo. La mayoría de tales entidades se formaban alrededor de los círculos y casinos de cultura burguesa. Luis Costa apunta tam-

40 LE BIGOT, Claude: «El movimiento coral en Asturias: etapa de recuperación (1923-1936)», en CARBOnell I Guberna, Jaume (Ed.): Els orígens de les associacions corals a Espanya, op. cit., p. 229, y «La recuperación del orfeonismo en Asturias (1923-1936», en URÍA, Jorge: Asturias. Historia y Memoria Coral, op. cit., pp. 114-116.

41 LE BIGOT, Claude: «El movimiento coral en Asturias», op. cit., p. 232.

42 Según el trabajo de CosTa VÁzQuEZ-MARIÑo, Luis: «El coralismo en Galicia: 1870-1930», en CARBONELl i Guberna, Jaume.(Ed.): Els origens de les associacions corals a Espanya, op. cit., pp. 157-177.

43 Ibid., p. 160. 
bién la importancia del fenómeno identitario de los repertorios, lo que acercaría el caso de los coros gallegos a los ejemplos catalán y vasco. Luis Costa también incide en el carácter conservador y religioso de algunas entidades, lo que nos recuerda las posiciones del Orfeó Català.

La intelectualidad nacionalista vio en la manifestación coral una expresión de galleguismo a promocionar como una de las bases importantes de la recuperación de identidad colectiva. Luis Costa indica al respecto que los vínculos entre los coros gallegos y el nacionalismo fueron muy estrechos, y explicaria la significación de afirmación nacional y recuperación cultural que se vivía en las actuaciones de las entidades corales ${ }^{44}$, una característica común a la que podríamos encontrar en el País Vasco y Cataluña, como lo hemos señalado anteriormente.

Castilla y Andalucía fueron tradicionalmente zonas poco coralizadas. El cuadro que aporta Joaquina Labajo en su trabajo sobre el canto coral en Valladolid es elocuente aunque sea provisional ${ }^{45}$. También hay que decir que a partir de los datos de que podemos disponer en la actualidad sobre el canto coral en Castilla, ya que el trabajo de Joaquina Labajo está centrado en Valladolid y la introducción no se refiere a Castilla sino a España, la zona de Castilla no está suficientemente tratada para poder extraer conclusiones significativas. Jacinto Torres Mulas, en su trabajo sobre el orfeonismo en España, facilita por su parte algunas pistas sobre actividad coral en Madrid que nos pone en evidencia la necesidad de profundizar en la cuestión ${ }^{46}$.

La limitada vida o la poca significación de tales manifestaciones corales puede ser una de las causas de esta laguna bibliográfica. Podemos aventurar la hipótesis que la falta de un tejido social favorable, es decir una presencia obrera capaz de nutrir un movimiento coral, como en Cataluña o Asturias, así como la falta también de aspiraciones nacionales, o de recuperación y cohesión cultural como podemos encontrar en Cataluña, País Vasco o Galicia, explicaría esta escasa coralización, ya que, como lo hemos dicho al principio, el canto coral es la expresión de las voluntades colectivas; y por tanto se daría más favorablemente en aquellas zonas en las que brotara una sensibilidad hacia un determinado proyecto cultural o nacional; o bien en aquellos colectivos necesitados de un instrumento de cohesión como el movimiento obrero.

Esto podría explicar la presencia en este territorio de los orfeones socialistas, cuyo caso paradigmático sería el Orfeón Socialista de Madrid, siendo bien conocidos los trabajos al respecto de Jean-Louis Guereña ${ }^{47}$. Según esta hipóte-

44 Ibid., p. 166.

45 LABAJO VALDÉs, Joaquina: Aproximación al fenómeno orfeonístico en España, op. cit., p. 99.

46 TORRES MULAS, Jacinto: «El origen de los orfeones y las sociedades corales en España», en TORReS MULAS, Jacinto (Ed.), El Romanticismo Musical Español, Ritmo. Cuadernos de Música, Madrid, 1982 .

47 GuEREÑA, Jean-Louis: «Les orphéons socialistes et leur répertoire au début du $\mathrm{XX}^{\mathrm{e}}$ siècle», op. cit., y «La formación de los orfeones socialistas», en CARBONELL I GUBERNA, Jaume (Ed.): Els orígens de les associations corals a Espanya, op. cit., pp. 83-94.

Hispania, LXIII/2, núm. 214 (2003) 485-504 
sis, vemos cómo, por ejemplo en Cataluña, los orfeones socialistas tuvieron una presencia muy limitada porque el panorama coral-asociativo estaba «copado» por las entidades claverianas-obreras, con una tradición cincuentenaria en el momento de las primeras fundaciones de los orfeones socialistas, y con una presencia aplastante en el panorama social y musical popular; y un movimiento orfeónico de signo nacionalista y conservador creciente.

El caso vasco en relación a los orfeones socialistas es distinto, porque la presencia de coros populares como podían ser los de Clavé en Cataluña no era tan generalizada. Pero en Castilla, donde no había una tradición coral arraigada (por lo menos en la misma medida que en el norte peninsular), el canto coral era funcional y se expandía a través de los Centros Obreros y las Casas del Pueblo, destinados a difundir y fomentar el discurso socialista. La poca implantación del P.S.O.E. en Cataluña también explicaría la limitada proliferación de orfeones de este signo en Cataluña, aunque también desconocemos la existencia de orfeones de signo anarquista, como apuntaba Michel Ralle ${ }^{48}$. Y no tenemos información que nos permita comparar la implantación de coros de signo burgués.

En Andalucía, la presencia coral fue muy limitada, también posiblemente por motivos parecidos a los que hemos apuntado en el caso castellano ${ }^{49}$. Joaquina Labajo localiza siete entidades solamente entre $1860-1890^{50}$. No disponemos de mucha información, pero gracias a los trabajos de Manuel Morales Muñoz sobre la situación en Málaga, sabemos de la influencia del modelo claveriano en la fundación de la sociedad coral La Estrella en 1863. Posteriormente, La Unión Coral Malagueña en 1887, y la Sociedad Coral de Málaga en 1913, ya con voces mixtas, entre otras entidades, vendrían a conformar un ejemplo de vida coral que compartiría con el Orfeón Obrero en $1912^{51}$. Desgraciadamente, no conocemos otras actividades corales en otras zonas andaluzas, pero podemos llegar a la conclusión que Málaga, y en cierta medida Sevilla, pueden ser los únicos centros andaluces donde se desarrolló una cierta actividad coral en el período que nos hemos marcado.

En resumen, y en líneas generales, diremos que en los diferentes conjuntos que conforman la España del siglo XIX y del primer tercio del XX, se dan diferentes experiencias corales, con cronologías y ritmos distintos, concepciones distintas, modalidades de estructura y fondos ideológicos distintos, composi-

48 RALLE, Michel: "Que el deleite sea provechoso, instructivo. Sociedades corales y rituales obreros hasta 1910", en CARBONELL I GUBERNA, Jaume (Ed.), Els orígens de les associacions corals a Espanya, op. cit., pp. 95-108.

49 Ver MORAlEs MUÑOZ, Manuel: «Sociedades musicales y cantantes en Andalucía (18431913)", Bulletin d'Histoire Contemporaine de l'Espagne, Bordeaux, $n^{\circ} 20$ [Sociétés musicales et chantantes en Espagne (XIX'-XX' siècles)], Diciembre de 1994, pp. 57-66.

so LABAJO VALDÉs, Joaquina: Aproximación al fenómeno orfeonístico en España, op. cit., p. 99.

51 MORALES MUÑOZ, Manuel: «Sociedades corales y orfeones en Málaga, 1853-1936», en CARBONELL I GUBERNA, Jaume (Ed.): Els orígens de les associacions corals a Espanya, op. cit., pp. 119-133. 
ciones sociales y objetivos a corto y largo plazo distintos, repertorios dispares y formaciones musicales variables.

Hay elementos comunes también. Estamos hablando de un fenómeno que se da en Europa con unas bases generales compartidas en las diferentes zonas en las que brota, y por tanto podemos observar los grandes puntos de coincidencia que podemos establecer con los coros alemanes o franceses: sentimiento nacional, y cohesión o conciencia social, identidad nacional o de clase, sea burguesa o proletaria, o ideológica en los coros políticos o religiosos. Pero estas líneas generales no se manifiestan de igual modo en todos las zonas enfocadas, porque estamos hablando de contextos sociales y económicos diferentes, de culturas diferentes, y de diferentes maneras de expresión de objetivos, experiencias e ideales, y en definitiva de concepciones de la sociedad diferentes. La difícil historia española de siglo XIX no se vio en toda la geografía de la misma manera ni generó las mismas reacciones ni las mismas esperanzas o revoluciones, como fue el caso de la Revolución del 1868 o la crisis del 98.

No podemos hablar pues de un período de formación o de nacimiento de las sociedades corales en España cuando básicamente el auge de los primeros años 1850-1860 solamente se da en Cataluña y parcialmente en Valencia o en Baleares. El período de plenitud que algunos historiadores señalan para 18701880 , que podría ser válido para Asturias, o Galicia en los años 1880, coincidiría con los años de crisis en Cataluña.

Las tipologías tampoco nos ayudan a hablar de generalidades. Cataluña tiene dos grandes grupos corales: sociedades corales claverianas y orfeones seguidores del Orfeó Català con tradiciones, historias, repertorios propios, etc. Por lo tanto, los Orfeones de Cataluña no pueden ser equiparables a los orfeones asturianos por su formación musical, sus objetivos, su ideología y su repertorio. El componente nacionalista los relacionaría con los vascos y gallegos pero encontraríamos matices en otros aspectos. Los orfeones de signo político como los socialistas o republicanos no tuvieron implantación en Cataluña, por lo menos no en la misma medida que en Castilla, en Asturias o en el País Vasco.

No podemos hablar tampoco de la formación coral en líneas generales. La introducción de las voces mixtas no se dio en la misma medida ni con la misma cronología ni criterio en todas las zonas, como tampoco podemos hablar de un repertorio común si exceptuamos algunas piezas emblemáticas propias de grupos sociales o ideológicos.

En definitiva, pensamos que no se puede hablar de un canto coral en España de manera generalizada porque no se puede cuadrar el círculo, aunque cabe apuntar la importancia de la sociabilidad coral y musical. La España del siglo XIX era, como la actual, la suma de diferentes realidades nacionales con manifestaciones culturales distintas, y por tanto con maneras diferentes de ver y entender el canto coral que se manifestó y tomó cuerpo de manera muy distinta en las diferentes zonas donde nació; vivió desarrollos diferentes como diferentes fueron las historias las formaciones sociales y las culturas de las surgió.

Hispania, LXIII/2, núm. 214·(2003) 485-504 
Pensamos que insistir en la diferencia es subrayar la obviedad, y que los caminos en la investigación tienen que partir de esta realidad.

Constatamos también la desigualdad de datos y de estudios. En este capítulo también vemos disproporciones. En Cataluña, en el País Vasco y en Asturias, nos consta la presencia de una historiografía muy completa en esta dirección, mientras que otras comunidades no están tan trabajadas. Posiblemente esto sea un reflejo también de la diversidad cultural, y la manera en que se percibe la importancia de una manifestación cultural en los diferentes conjuntos españoles denota la idea que se tiene, lo que fue y representa esta manifestación para cada colectivo. 